\title{
ESPACIOS EXPOSIIIVOS
}

\section{STOP MOTION DON'T STOP LA EXPOSICIÓN}

\author{
Beatriz Herráiz Zornoza
}

Universitat Politècnica de València

En 2013, y durante apenas dos meses, pudo verse en el MuVIM de Valencia la exposición Stop Motion Don't Stop, una exposición comisariada por MacDiego, en la que se mostró el trabajo de tres productoras de animación stop-motion afincadas en Valencia, actualmente produciendo series y películas que compiten a nivel internacional. Javier Tostado, Sam y Pablo Llorens, al mando respectivamente de Clay Animation, Conflictivos Productions y Potens Plastianimation, nos acercaron a sus creaciones, sus estilos y sus métodos de trabajo. Además en la exposición se llevó a cabo una parte de la producción de Clay Kids, donde todo el equipo estuvo trabajando ante los visitantes. El siguiente artículo nos adentra en las tres décadas de producción de animación valenciana, a partir de esta exposición que ha rendido un justo homenaje a su calidad artística.
In 2013 and for barely two months, it was seen in the Valencian MuVIM the exhibition Stop Motion Don't Stop, curated by MacDiego, which reunited the work of three stop motion animation production companies settled down in Valencia. These companies are featuring now series and films which compete at international level. Javier Tostado, Sam and Pablo Llorens, commanding Clay Animation, Conflictivos Productions and Potens Plastianimation respectively, brought us their creations, their styles and their working methods. Also, in the exhibition was carried out part of the production of Clay Kids, with the whole team working in front to the visitors. The exhibition delved into three decades of animation production in Valencia, where we could discover their high degree of creative quality. 


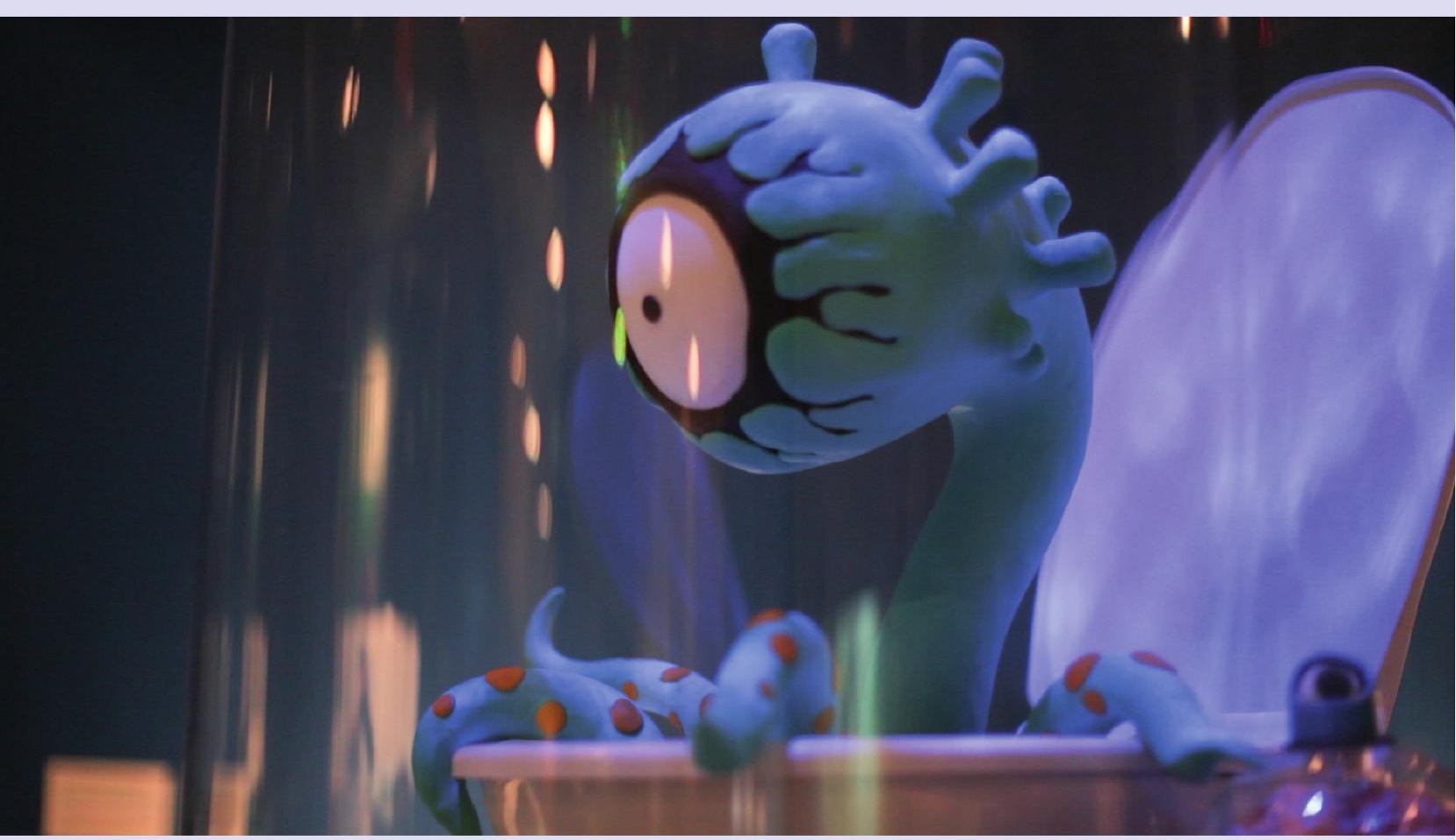

Fig. 1 - Stop Motion Don't Stop. Modelo original de plastilina para el mutante alienígena de Molecular Zombie (Pablo Llorens, 2012)

2013 fue un año importante para el stopmotion, ya que tres de los cinco largometrajes que optaron a los Oscar estaban realizados en esta técnica: Frankenweenie, The Pirates! y $\mathrm{Pa}$ raNorman, aunque ninguno de ellos se hizo con la estatuilla. También en mayo de ese año despedimos a una de las figuras más elogiadas de la animación de muñecos, Ray Harryhausen, el maestro de los efectos especiales que consagró la técnica en numerosas producciones del Hollywood de entre los años 40 y 80 .

En este contexto, y sin que se puedan hallar precedentes relevantes de una exposición de estas características en España, se inaugura en el MuVIM ${ }^{1}$ STOP MOTION DON'T STOP, una retrospectiva de los animadores, directores y productores más destacados de la animación stop-motion realizada en Valencia.

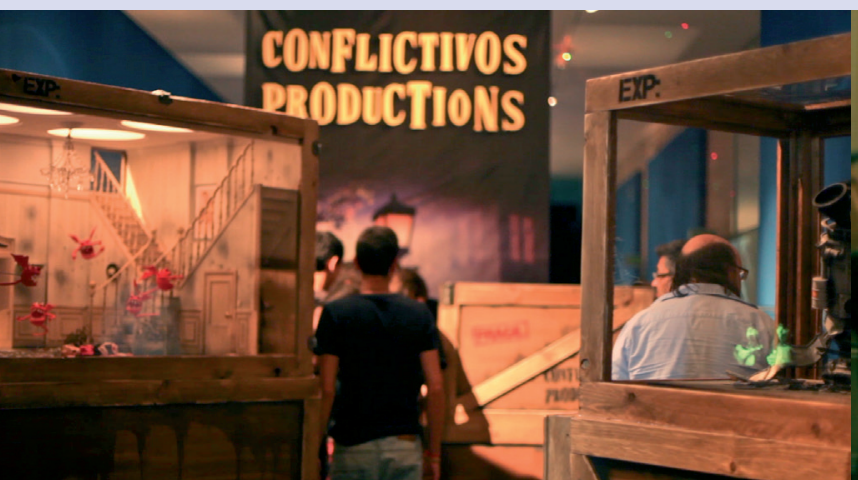

Fig. 2 - Stop Motion Don't Stop. Sala Conflictivos Productions

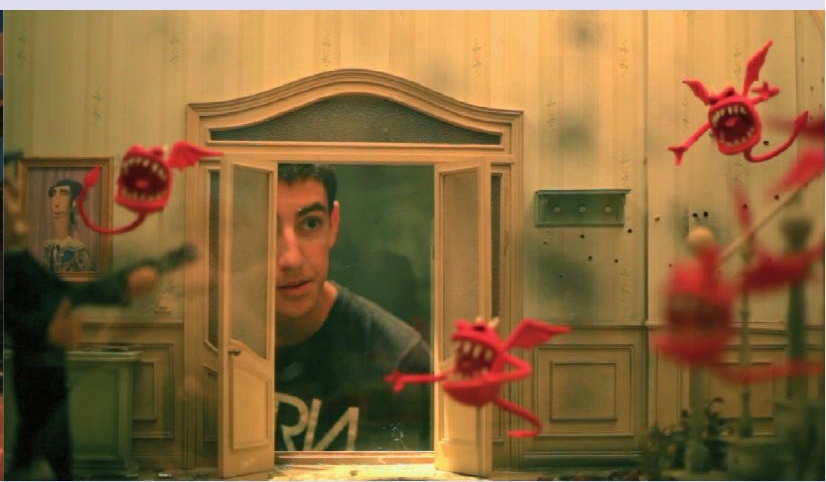

Fig. 3 - Stop Motion Don't Stop. Diorama de Pos Eso (Sam, 2014) en la exposición 


\section{1}

La exposición

Comisariada por MacDiego y avalada por el éxito de Paco Roca, dibujante ambulante -inaugurada tan sólo unos meses antes en el mismo museo-, la exposición se pudo visitar durante apenas ocho semanas, pero batió records de asistencia con más de 25.000 visitantes.

Diseñador de profesión, irreverente de vocación, agitador por convicción y con un don visionario, parece que MacDiego, el Midas del comisariado en Valencia, convierte en éxito aquello cuanto toca. El sello MacDiego pudo verse en la concepción y la cuidada puesta en escena de la exposición, quien consiguió como por arte de magia lo que la museología lleva lustros persiguiendo: convertir el museo en un ente vivo, ya que en la exposición no sólo se pudieron ver las piezas de los animadores valencianos a través de los cristales de las vitrinas, sino que los visitantes pudieron conocer los entresijos de una producción de stop-motion en directo. Además, durante la exposición estuvo en activo la realización de un cadáver exquisito, ${ }^{2}$ donde quien quisiera podía animar una secuencia con la única condición de comenzar la animación donde el anterior animador lo había dejado.

Para esta exposición se habilitó la sala Alfons Roig, dividida en cinco espacios dedicados a los protagonistas más prolíficos de la producción valenciana. Un primer espacio presentaba la exposición a través de una pequeña pieza animada en plastilina, realizada por Pablo Llorens, que compartía protagonismo con los muñecos y decorados de Història d'Este (Pascual Pérez, 2011) y El Felipe y La Mari Pepa (Manuel Ferri, 2005). Junto a éstos, un gran panel nos mostraba el cronograma de todos los periodos del stop-motion valenciano. Las otras tres salas estaban dedicadas respectivamente a Javier Tostado (Clay Animation), Sam (Conflictivos Productions) y Pablo Llorens (Potens Plastianimation).

En pleno rodaje de Clay Kids, Javier Tostado abandonó durante dos meses sus cómodas instalaciones en Ribarroja para trasladar los decorados, el equipo de rodaje, los muñecos, 
los animadores, con el director de animación David Caballer al frente, y el equipo de postproducción a la sala de exposiciones, donde intentaron mantener el frenético ritmo de trabajo al que están acostumbrados. Clay Kids es una serie de 52 episodios de 11 minutos cada uno, y ha sido animada íntegramente en Valencia. La serie, galardonada con el Silver Telly Award, los Oscar@ de la televisión, tiene su origen en El ladrón navideño, el primer cortometraje de Tostado que además funcionó como "teaser" de la misma.

Por su parte, Sam, que también se encontraba en plena realización de Pos eso, su última producción en forma de largometraje, desempolvó gran parte de sus decorados y protagonistas, deleitándonos con no pocas de sus más delirantes escenas, un derroche de barroquismo cañí para ser contemplado de cerca y no perderse ninguno de sus detalles: allí podían verse la Benemérita, la Iglesia más recalcitrante, amas de casa enajenadas, bares mugrientos de barrio obrero, Encarnas y Vicentas que, al ritmo de copla, podrían encarnar las más sangrientas escenas de Quentin Tarantino, pero a la española.
Parte de estas piezas ya pudieron ser contempladas en la exposición Un mundo en miniatura, con motivo de la Semana de Cine Fantástico y de Terror celebrado en Donostia en 2012.

En la última sala de la exposición, Pablo Llorens nos transportaba a su particular mundo alienígena, repleto de extraterrestres, monstruos viscosos de todas las clases, científicos extravagantes y algún que otro terrícola. Pablo Llorens, como veremos con más detenimiento a continuación, ha sido y sigue siendo una pieza clave en la producción de stop-motion en Valencia.

\section{2}

Pablo Llorens: en el epicentro de la producción durante tres décadas

Algunos de estos creadores escriben la historia reciente del stop-motion de la capital del Turia, lo que algunos llaman la "California del stop-motion", pero sus orígenes se anclan unas décadas atrás, en plena euforia de los años 80 . Durante este periodo y la década de los 90, la

Fig. 5 - Stop Motion Don't Stop. Set de Gastropotens II. Mutación tóxica (Pablo Llorens, 1994)

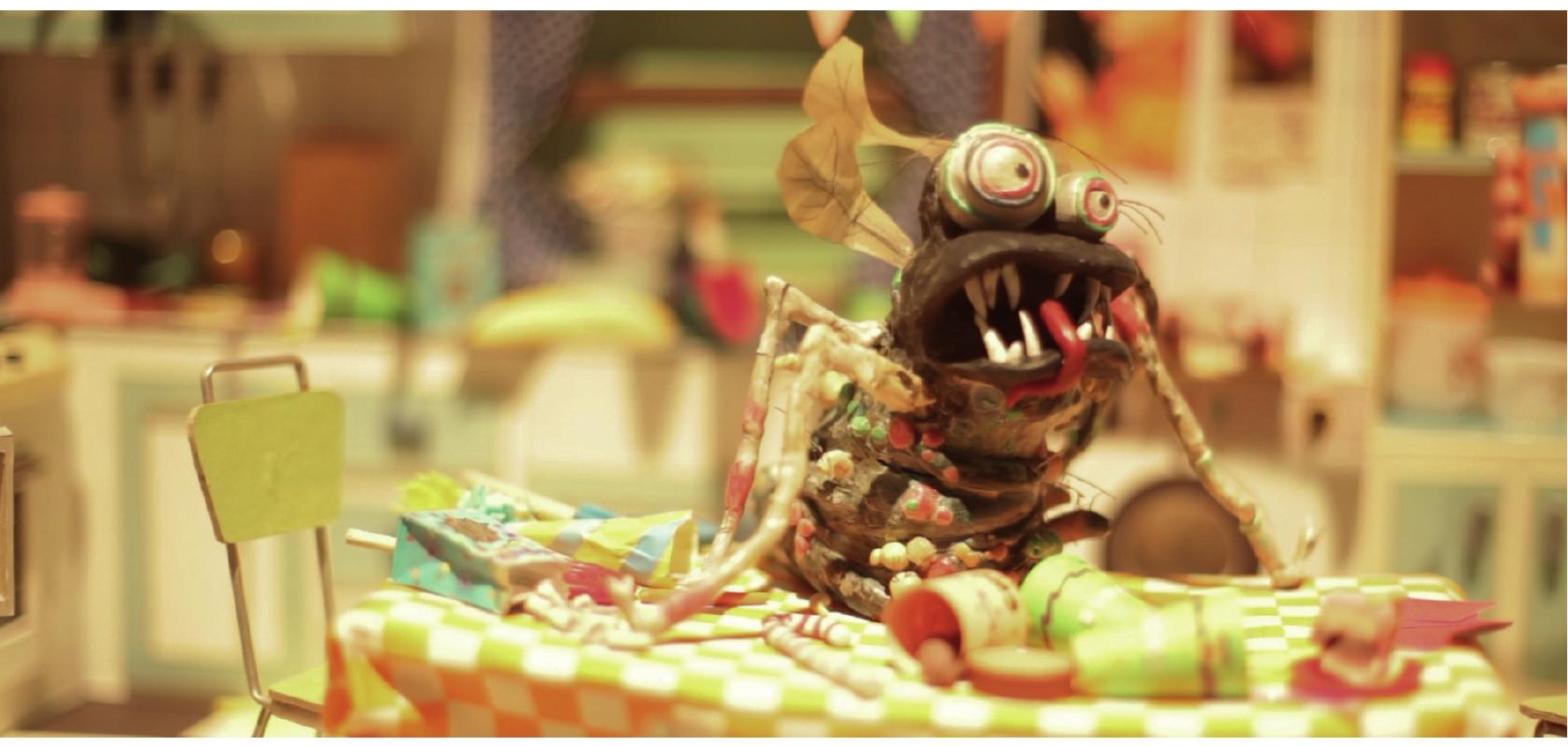




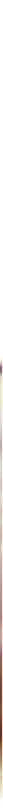

Fig. 6 - Stop Motion Don't Stop. Sala Clay Kids

producción en stop-motion valenciano gira en torno a tres productoras: Tirannosaurus, Pasozebra y Truca Films, y sobre todo, en torno a Pablo Llorens, alrededor del cual se genera una verdadera escuela en la técnica de plastilina, de la que surgen autores como Enric Cuéllar o Raúl Díez. ${ }^{3}$

Con dos premios Goya en sus vitrinas, Pablo Llorens ha sido el auténtico motor de la animación de muñecos en Valencia, estando presente en casi todas las producciones valencianas, donde ha compartido saberes con todos los animadores de la tierra. Pero también ha colaborado en otras producciones stop-motion como Los García, campaña que promovió el Ministerio de Economía y que se realizó en Madrid en 2001. $\mathrm{Ha}$ realizado numerosos cortometrajes como Gastropotens Iy II (1990 y 1994 respectivamente), La niña está llorando (1992), sus más recientes Chokopulpitos (2008) y El ultimátum evolutivo (2009), o Caracol col col (1995), con el que obtuvo el primero de sus Goyas. Diez años más tarde se hacía de nuevo con este premio por $E l$ enigma del chico croqueta (2004). Además ha rea- lizado varios largometrajes como Juego de niños y series televisivas como Pérez y Donato (1996) y Doc Franky (1999), tarea que ha combinado con la realización de videoclips y numerosas campañas publicitarias, como las que lleva produciendo para Halo Megabloks en los últimos años.

Es incapaz de traicionar su propio estilo, que no se pliega a las convenciones o gustos mayoritarios: un estilo particular que bebe de las películas de serie $B$, de la ciencia ficción, de las series sesenteras y setenteras de invasiones alienígenas y luchas interestelares, o de la más casposa imaginería televisiva - aunque esto no está reñido con un discurso mordaz frente a la sociedad alienada y de consumo, o hacia el espectáculo mediático televisivo- Sus protagonistas, normalmente inadaptados, lidian con extraterrestres repletos de tentáculos y grandes bocas abarrotadas de dientes, o con científicos sin escrúpulos que utilizan a la humanidad como conejillos de indias, todo esto aderezado con una buena dosis de humor. Y es que la animación de Pablo Llorens es tremendamente intuitiva y en ocasiones poco ortodoxa, un estilo 


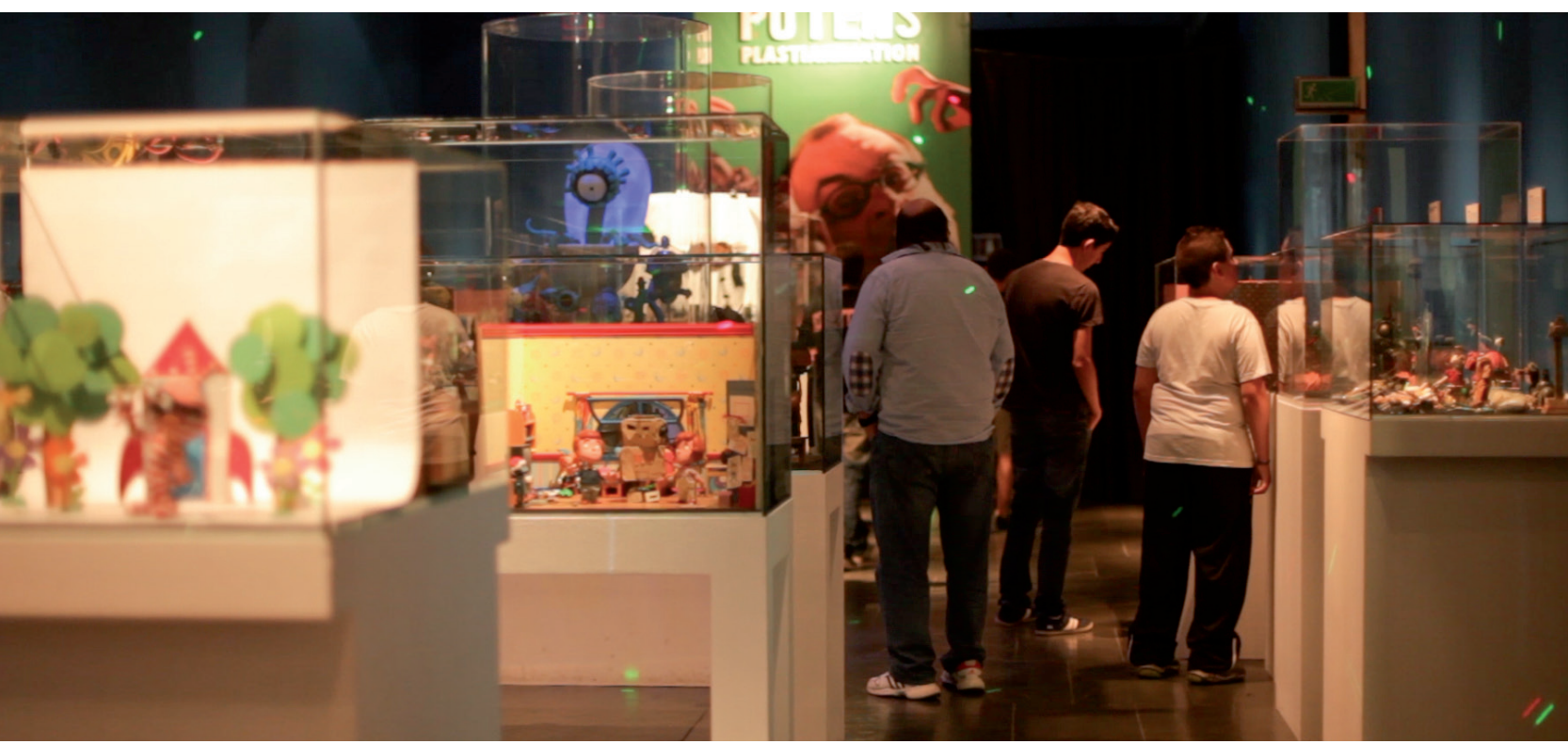

Fig. 7 - Stop Motion Don't Stop. Sala Potens Plastianimation

de hacer cine que le sale de los jugos gástricos, más que de técnicas excesivamente depuradas.

\section{3}

Animación valenciana:

la reconstrucción de los hechos

Siguiéndole el rastro a Pablo Llorens se puede descubrir la historia del stop-motion en $\mathrm{Va}$ lencia, que, con cierto aire de culebrón, todo sea dicho, se reconstruye a partir de los testimonios de muchos colaboradores y protagonistas en la publicación homónima a la exposición, un volumen que en sus 335 páginas recoge un buen puñado de acontecimientos y anécdotas, que nos permiten revivir los inicios y momentos clave de su recorrido.

En las páginas de STOP MOTION DON'T $S T O P$, el lector podrá descubrir los motivos que desencadenaron la creación de sus productoras, y también las causas de la desaparición de otras o la mutación hacia otras técnicas; así como la colaboración con artistas de otros gremios, la aparición de nuevos talentos que iban evolucionando las técnicas de animación, el trabajo en equipo con animadores, directores de fotografía, guionistas, productores, etc. También permite conocer la colaboración con instituciones que han apoyado este tipo de cine, o las idas y venidas de los animadores de unos proyectos a otros. Según Fernando Millán,

es en Valencia donde, no se sabe muy bien por qué (aunque hay unas cuantas teorías), desde más o menos 1993-1994 existe una masa crítica de estudios de animación de stopmotion que se mantiene constante, relevándose unos a otros o evolucionando sobre sí mismos enredados por una telaraña de personas que fluye entre ellos manteniendo cierta cohesión tensa. ${ }^{4}$

Fueron los tiempos del super 8, del $16 \mathrm{~mm}$, del Betacam e incluso del VHS. En unos años se pasó prácticamente del paso de manivela, propio de la producción analógica, a la captura remota con Dragonframe, y de las aparatosas 


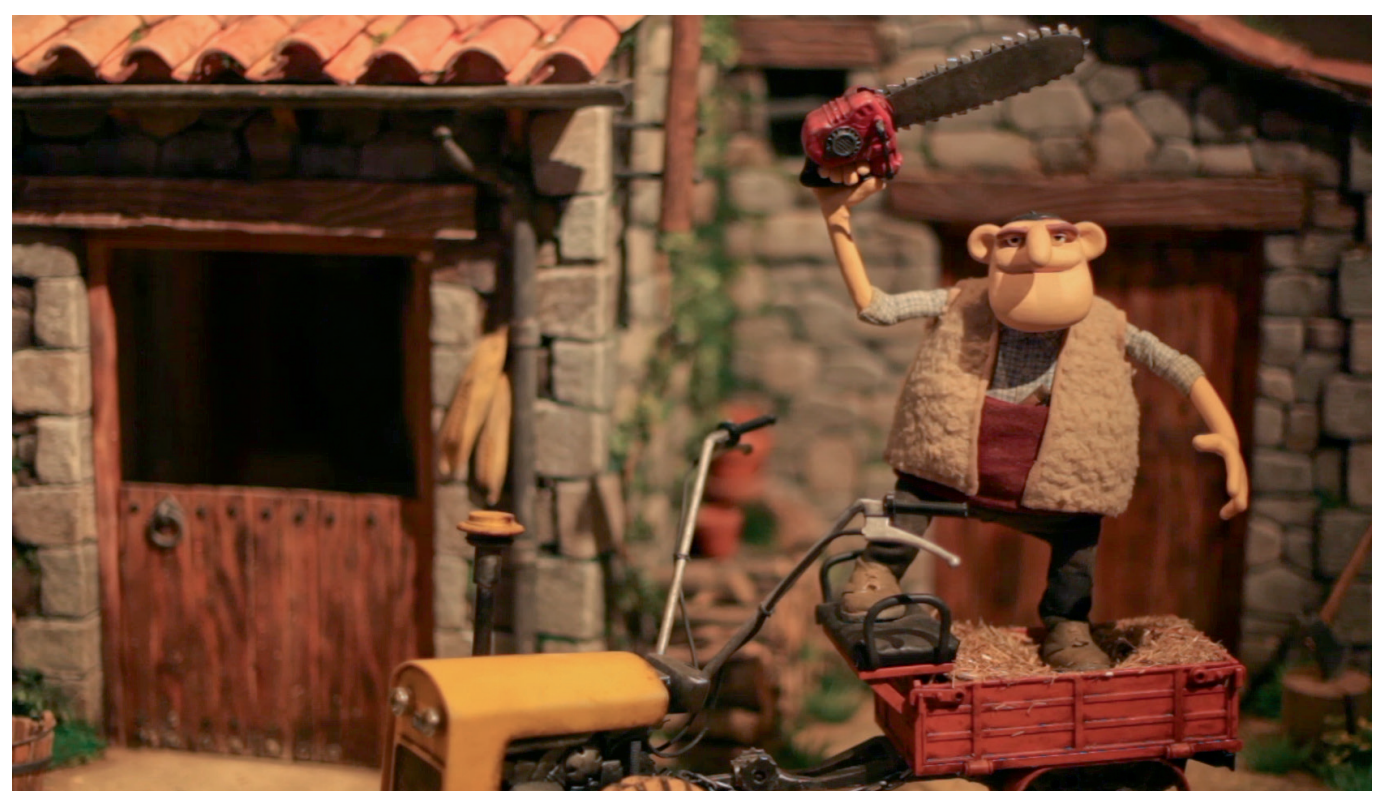

Fig. 8 - Stop Motion Don't Stop. The Werepig (Sam, 2008)

cámaras de cine o de video digital a las pequeñas dimensiones de las DSLR. También los materiales han cambiado considerablemente, pasando de esqueletos de alambre a estructuras complejas articuladas; o de una materia inestable como es la plastilina, a materiales flexibles como la espuma de látex o la resina para los "props”, complementos y escenarios, y otros sistemas como la sustitución de ojos y bocas, que han ido mejorando poco a poco los procesos de animación.

Muchos de nuestros animadores han trabajado y siguen trabajando para Aardman Animations, donde el trasvase de conocimientos entre éstos y la conocida productora ha sido mutuo, constante y crucial para el desarrollo y tecnificación del stop-motion en Valencia. Diego Soriano confiesa a MacDiego en una entrevista recogida en el libro:

de España se sale preparado para trabajar en cualquier sitio. Somos guerreros que nos adaptamos a cualquier situación y a trabajar en condiciones extremas. Los de Aardman no están preparados para venir a trabajar aquí... (risas) Aquí tienes que pensar en todo y comerte la cabeza para solucionar problemas de espacio, materiales, herramientas...

El primer cortometraje valenciano en aplicar todas estas técnicas fue el mencionado El ladrón navideño, para el que Javier Tostado montó en el año 2000 un equipo mixto de animadores valencianos e internacionales. La mayoría de ellos había pasado por Aardman Animations, y entre ellos estaban Kevin Wright, Kim Keukeleire, Mike Cash, Sam y Pascual Pérez. El resultado fue uno de los primeros cortometrajes españoles capaz de emular la alta calidad de la productora inglesa, inaugurando una nueva forma de hacer stop-motion en nuestro país.

Para completar el panorama valenciano del stop-motion, no seríamos del todo justos si no nombráramos a figuras como David Caballer, Enric Cuellar, Raúl Díez, Miquel Mestre, Daniel Díez, Pancho Monleón, Paco Ibáñez, Juan Padrón, Roberto Canelles, Paco Gisbert, así como algunas instituciones como Cinema 
Jove, la facultad de Bellas Artes de Valencia, la Escuela de Cine de Puçol, el Festival de Cine y Vídeo Amateur de Quart de Poblet, y la ya desaparecida RTVV. Todos ellos han contribuido de una manera $u$ otra a que el stop-motion lleve produciéndose en Valencia más de tres décadas.

\section{4}

Una reivindicación necesaria

Si comenzábamos este texto hablando de los acontecimientos que marcaron el 2013, no podemos pasar por alto la desaparición del canal público de Radio Televisión Valenciana, RTVV, que deja huérfano nuestro patrimonio audiovisual. Durante varias décadas, esta televisión ha estado presente en la realización de innumerables producciones tanto de imagen real como de animación: series como Nappy, el guerrero verde, Caracolimpicos, Trickes o Doc Franky, y tantos otros cortometrajes, nunca habrían visto la luz sin el respaldo del ente televisivo. Canal 9 ha contribuido durante años a visibilizar y apoyar la producción en stop-motion en la Comunidad Valenciana: gran parte de la historia de la animación en Valencia tuvo lugar gracias a la inversión de nuestra televisión pública y, aunque en los últimos años se había visto muy mermada, esta ausencia traerá consecuencias severas para nuestro sector audiovisual, condenándolo a un escuálido futuro.

\section{5}

E1 resultado de una retrospectiva

Las causas que desencadenaron esta concentración de animación de stop-motion en este pequeño y remoto lugar del mundo son inciertas, pudiendo ser motivos fortuitos, caprichos cinematográficos, o locuras transitorias, pero su permanencia en el tiempo atiende a una fórmula clara que conjuga el esfuerzo, la perseverancia y la pasión de sus protagonistas.
Estas tres décadas de experiencia han hecho que actualmente la calidad de animación que se realiza en Valencia sea impecable y pueda exportarse fuera de nuestras fronteras. Aunque no sabemos si en algún momento llegará a consolidarse una industria.

STOP MOTION DON'T STOP salda una deuda de la sociedad valenciana y española frente a todos estos creadores altamente cualificados y reconocidos, más frecuentemente fuera de nuestras fronteras, acercando esta técnica al público en general, y en especial al público infantil, que ha podido disfrutar de una nueva experiencia en el museo de manera viva. Por lo pronto, más de veinte mil personas están ahora más sensibilizadas ante este fenómeno y sabrán apreciar mejor estas producciones. Si este tipo de eventos son más comunes en otros lugares, esperemos poder ver exposiciones de cada una de las producciones de todos estos creadores y esperemos que, pese a las dificultades de llevar adelante estos proyectos, podamos seguir celebrando la calidad de la animación valenciana; y también, en palabras de Sam, "esperemos que la animación en España comience a exportar más animación y deje de exportar profesionales”.

(C) Del texto: Beatriz Herráiz Zornoza.

(C) De las imágenes: Figs. 1, 2 y 8: Conflictivos Productions; Figs. 4, 5 y 6: Potens Plastianimation; Fig. 7: Clay Animations. Exposición: MuVIM, MacDiego. Fotografías: Beatriz Herráiz Zornoza. 


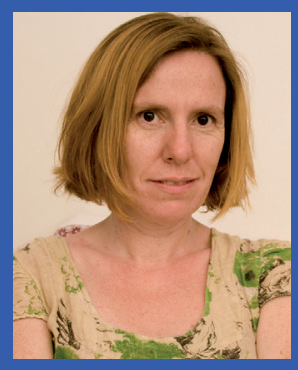

\section{Biografía}

Beatriz Herráiz Zornoza (Valencia, 1975). Doctora Cum Laude por la Facultad de Bellas Artes, Universitat Politècnica de València. Actualmente es Profesora ayudante doctor en el Grado en Comunicación Audiovisual y en la Facultad de Bellas Artes de Valencia. Ha trabajado como diseñadora gráfica para Canal $9 \mathrm{y}$ UPVRTV, desarrollando proyectos audiovisuales para identidad de cadena, programas e informativos. Su línea de investigación se centra en el "motion graphics" y la animación, realizando publicaciones para el Congreso de Tipografía 2012, y CONFIA 2013. Además, ha sido la coordinadora de un proyecto de cooperación internacional titulado Historias para compartir, con el Conservatorio Balla Fasseke Kouyate de Bamako (Mali). Ha realizado el diseño audiovisual escenográfico de diferentes obras de teatro, como Bonnie y Clyde (Teatro Galo Real), Dot y Consonants (Maduixa Teatre) y Harket Protocolo (PanicMap), estas dos últimas con circuito internacional. Actualmente es miembro del Grupo de investigación en Animación: Arte e Industria.
Notas

1 Museu Valencià de la Il·lustració i la Modernitat. 2 Este cadáver exquisito se puede visionar en http://www.youtube.com/watch?v=h2UYq-q8U_0 3 DE LA ROSA, Emilio, 2003. "Cine de animación en España”, en Bendazzi, Giannalberto, Cartoons. 110 años de cine de animación, Madrid: Ocho y Medio, p. 505.

${ }^{4} \quad$ MuVIM (eds), 2013, STOP MOTION DON'T STOP, Valencia: Diputació de València, Museu Valencià de la Il-lustració i la Modernitat, p. 61.

5 Ibídem, p. 80.

\section{E-mail}

beaherzo@doctor.upv.es 